\title{
The National Spallation Neutron Source Target Station: A General Overview
}

Tony A. Gabriel, John N. Barnes, Lowell A. Charlton, James DiStefano, Ken Farrell, John Haines, Jeffrey O. Johnson, Louis K. Mansur, Steve J. Pawel, Moshe Siman-Tov, Rusi Taleyarkhan

Oak Ridge National Laboratory", P. O. Box 2008, Oak Ridge, Tennessee 37831, USA

Thomas J. McManamy, Mark J. Rennich

Engineering, Lockheed Martin Energy Systems, Inc., P. O. Box 2009, Oak Ridge, Tennessee 37830, USA

"This submitted manuscript has been authored by a contractor of the U.S.

Government under Contract No. DE-AC05

960R22464. Accordingly, the U.S.

Government retains a nonexclusive, royalty-free license to publish or reproduce the published form of this contribution, or allow others to do so, for U.S. Government purposes."

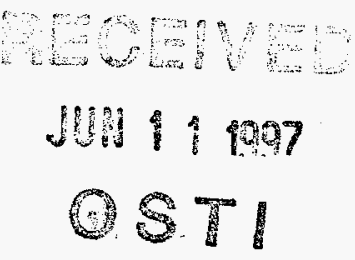

May 12-16, 1997

\section{DISTRIBUTION OF THIS DOCUMENT IS UNLIMITED}

* Managed by Lockheed Martin Energy Research Corporation for the U.S. Department of Energy under Contract No. DE-AC05-96OR22464. 


\section{DISCLAIMER}

This report was prepared as an account of work sponsored by an agency of the United States Government. Neither the United States Government nor any agency thereof, nor any of their employees, make any warranty, express or implied, or assumes any legal liability or responsibility for the accuracy, completeness, or usefulness of any information, apparatus, product, or process disclosed, or represents that its use would not infringe privately owned rights. Reference herein to any specific commercial product, process, or service by trade name, trademark, manufacturer, or otherwise does not necessarily constitute or imply its endorsement, recommendation, or favoring by the United States Government or any agency thereof. The views and opinions of authors expressed herein do not necessarily state or reflect those of the United States Government or any agency thereof. 


\section{DISCLAMMER}

Portions of this document may be illegible in electronic image products. Images are produced from the best available original document. 


\section{THE NATIONAL SPALLATION NEUTRON SOURCE TARGET STATION: A GENERAL OVERVIEW}

Tony A. Gabriel, John N. Barnes, Lowell A. Charlton, James DiStefano, Ken Farrell, John Haines, Jeffrey O. Johnson, Louis K. Mansur, Steve J. Pawel, Moshe Siman-Tov, Rusi Taleyarkhan

Oak Ridge National Laboratory, P. O. Box 2008, Oak Ridge, Tennessee 37831, USA

Thomas J. McManamy and Mark J. Rennich

Engineering, Lockheed Martin Energy Systems, Inc., P. O. Box 2009, Oak Ridge, Tennessee 37830, USA

\section{Abstract}

The technologies that are being utilized to design and build a state-of-the-art neutron spallation source, the National Spallation Neutron Source (NSNS), are discussed. Emphasis is given to the technology issues that present the greatest scientific challenges. The present facility configuration, ongoing analysis and the planned hardware research and development program are also described.

\subsection{INTRODUCTION}

In many areas of physics, materials and nuclear engineering, it is extremely valuable to have a very intense source of neutrons so that the structure and function of materials can be studied. One facility proposed for this purpose is the National Spallation Neutron Source (NSNS). This facility will consist of two parts: 1) A high-energy $(1 \mathrm{GeV})$ and high powered $(1 \mathrm{MW})$ proton accelerator ( $60 \mathrm{Hertz},<1 \mu \mathrm{s} /$ pulse), and 2) A target station which converts the protons through nuclear interactions to low-energy $(\leq 2 \mathrm{eV})$ neutrons and delivers them to the neutron scattering instruments.

This paper deals with the second part, i.e., the design and development of the NSNS target station and the scientifically challenging issues. Many scientific and technical disciplines are required to produce a successful target station. These include engineering, remote handling, neutronics, materials, thermal hydraulics, and instrumentation. Some of these areas will be discussed below.

\subsection{TARGET STATION CONFIGURATION AND MAINTENANCE}

The target for the NSNS is located in a single building. As shown in Fig. 1, the target is positioned within an iron and concrete shielding monolith approximately $12 \mathrm{~m}$ in diameter. The proton beam enters horizontally in the mercury target and produced neutrons, which (after moderation) are used by the scattering instruments, exit through 18 neutron beam tubes projecting from the sides. The majority of the $62 \mathrm{~m} \mathrm{x} 83$ $\mathrm{m}$ building is reserved for the scattering instruments located on the neutron beam lines, however, remote handling hot cells projecting from the back of the shielding are provided for handling the activated target, moderator and reflector components. This region also contains utilities used for the target. Another cell for utility systems is located beneath the main floor level.

The reference design for the NSNS incorporates mercury as its target material. A heavy liquid metal target was selected over a water-cooled solid target because (1) increased power handling capability is possible with a liquid target, (2) the liquid target material lasts the entire lifetime of the facility, and (3) the radiation damage lifetime of a liquid target system, including its solid material container, should be considerably longer.

Mercury was also selected as the reference liquid target material because it: (1) is a liquid at room temperature, (2) has good heat transport properties, and (3) has high atomic number and mass density resulting in high neutron yield and source brightness. One significant result from recent neutronic analysis studies has been that the neutron flux from a short-pulse $(\sim 1 \mu s)$ neutron source is substantially greater for a mercury target than for either water-cooled tungsten or tantalum targets especially at power levels greater than $1 \mathrm{MW}$.

The mercury target design configuration, shown in Fig. 2, has a width of $400 \mathrm{~mm}$, a height of $100 \mathrm{~mm}$, and a length of $650 \mathrm{~mm}$. The mercury is contained within a structure made from 316-type stainless steel. Mercury enters from the back side (side outermost from the proton beam window) of the target, flows along the two side walls to the front surface (proton beam window), and returns through a $224 \mathrm{~mm} \times 80 \mathrm{~mm}$ rectangular passage in the middle of the target. The target window, i.e., portion of the target structure in the direct path of the proton beam is cooled by mercury which flows through the passage formed between two walls of a duplex structure. In this way, the window cooling and transport 


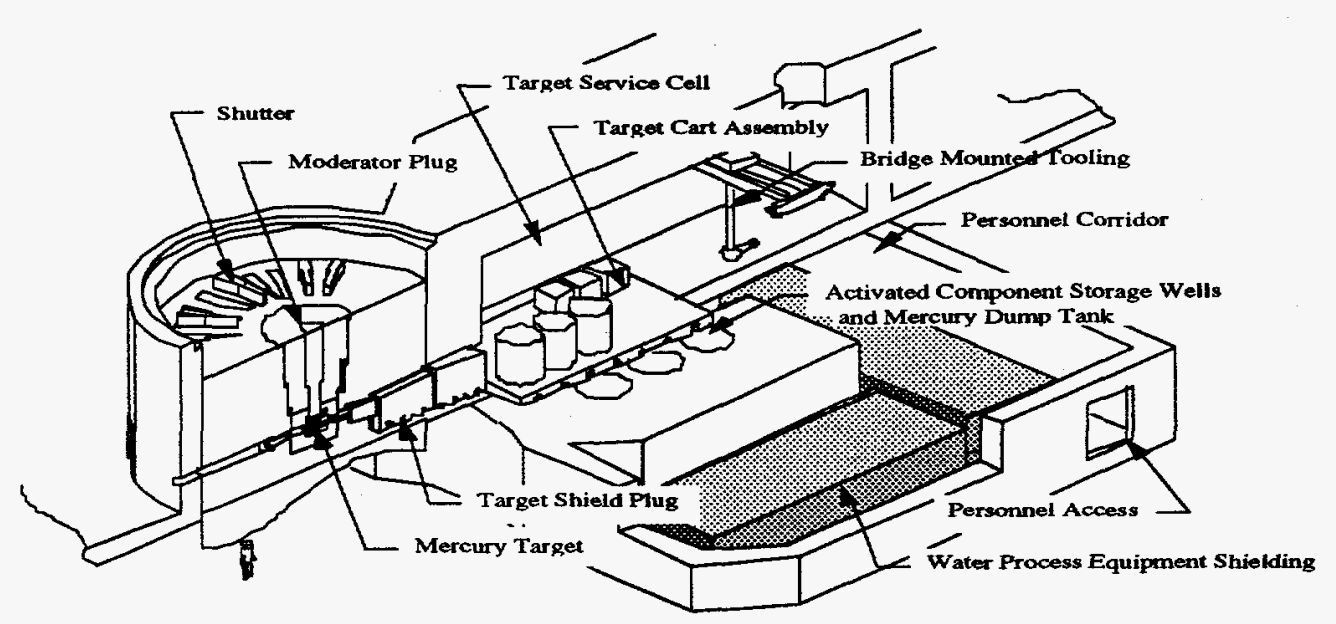

of heat deposited in the bulk mercury are achieved with separate flow streams.

A shroud (safety container) is provided around the mercury target to guide the mercury to a dump tank in the event of a failure of the target container structure. The shroud is a water-cooled duplex structure made from austenitic, 316-type, stainless steel.

Detailed thermal hydraulic and stress calculations have been carried out for the mercury target system and a large fraction of our R\&D program deals with thermal shock and hydraulic tests and analysis, radiation damage, and erosion/corrosion test and analysis.

The mercury target and the water cooled shroud, which are subject to intense interactions with the proton beam, must be replaced on a regular basis. For this reason, all major liquid target system components, except the dump tank, are located on a mobile cart, which is retracted into the target maintenance cell for maintenance activities. The mercury contained in the target system is drained to the dump tank prior to retracting the target assembly.

The heat deposited in the mercury target is transported away in the flowing mercury loop to a primary heat exchanger that is located on the target cart assembly, outside the target region shielding. In addition to this primary heat exchanger, the mercury flow loop also includes piping, valves, fittings, pumps, expansion tanks, and mercury processing equipment. The secondary (water) loop transports the heat to a secondary heat exchanger located in the floor below the target hot cell. The tertiary flow stream utilizes process water.

The mercury dump tank is located below all other components in the mercury system thus ensuring that most of the mercury can be drained to the dump tank even in a passive situation (failure of the electric power system). The capacity of the dump tank is greater than 1 $\mathrm{m}^{3}$, which is slightly larger than the mercury inventory in the remainder of the system. The tank is passively cooled by natural convection to remove the nuclear afterheat in the mercury.

Figure 2 shows the two light-water moderators planned for the NSNS. They are located in wing geometry below the mercury target and water-cooled shroud. The upstream moderator has a thickness of $50 \mathrm{~mm}$, relative to the proton beam, and is decoupled and poisoned to give high temporal resolution of the neutron flux. The second moderator is $100 \mathrm{~mm}$ thick and is coupled to produce higher neutron intensity but with less temporal resolution. Both moderators are approximately $120 \mathrm{~mm}$ wide and $150 \mathrm{~mm}$ high. Two cryogenic moderators, cooled with supercritical hydrogen, are located above the target as shown in Fig. 2. This configuration improves the cooling and warming characteristics of the moderators. Mechanically circulated supercritical hydrogen gas at a pressure of 1.5 MPa was chosen for the moderators because it improves the cooling operation, eliminates boiling and adds flexibility in operation. The hydrogen is maintained at supercritical pressures in all parts of the loop during normal operation. The calculated neutron current energy distribution per proton from the front cryogenic moderator is shown in Fig. 3.

The neutron beam tube systems provide the paths for moderated neutrons to travel through the bulk shielding to the scattering instruments. The configuration assumed at present consists of 18 beam lines looking at the four moderators as shown in Figs. 1 and 2. Each moderator face which is viewed illuminates three beam lines, one normal to the face and two at plus or minus 13.75 degrees. The upper and lower forward moderators have two faces viewed and the two rear moderators each have one face viewed for a total of 6 viewed faces. This arrangement allows a $70^{\circ}$ degree arc for the proton beam entrance region and a similar $70^{\circ}$ degree arc for the remote maintenance systems at the rear of the target. 
Fig. 2: NSNS Mercury Target

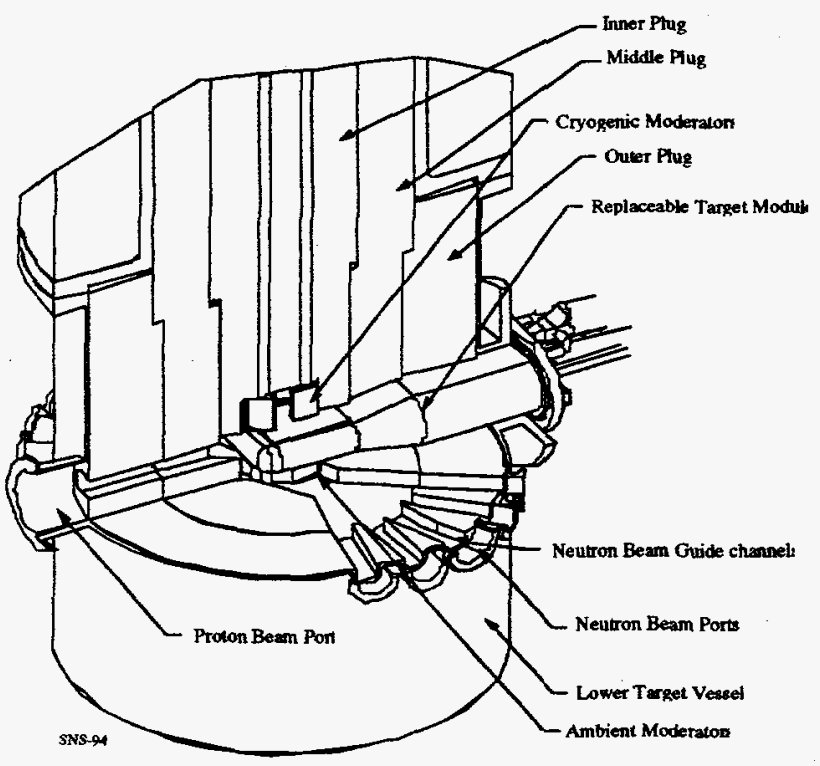

A neutron beam shutter concept similar to the ISIS vertical shutter design is planned. The shutters are in the form of stepped rectangular slabs. In the open position a hole in the shutter aligns with the neutron beam flight path and cross section. The shutter is lowered approximately $500 \mathrm{~mm}$ to close. This puts approximately $2 \mathrm{~m}$ of shielding in the neutron flight path. The drive for the shutters will be from the top. Each shutter will be made from several sections to reduce the height above the top of the bulk shielding required for removal and the size of the shielded flask required for transport. All shutters will be the same, except for the difference in beam elevation required between beam lines viewing the upper or lower moderators. The weight of one shutter assembly is approximately 25 tonnes.

Optimization of both the operating availability and predictability, while protecting personnel, is the primary goal of the maintenance systems for NSNS. Several techniques proven in successful facilities throughout the world are applied to assist the operators in meeting the operating goals. These include designing equipment from the earliest stages to reduce the need for remote handling. Operating equipment are packaged in modular assemblies designed to be replaced with on-site spares. This enables operations to continue while time-consuming repairs are performed in off-line facilities.

The As Low As Reasonably Achievable (ALARA) principle is used as guidance for all personnel and contamination control operations in NSNS. Thus, activated and contaminated equipment are shielded for transport around the facility and to the permanent storage site. Areas of potential contamination are isolated by seals and valves. Repair and replacement of active components are accomplished in the hot cell adjoining the target shielding stack as identified in Fig. 1.
Fig. 3: Neutron energy distribution from the face of the front cryogenic moderator, $C=$ coupled, $P=$ poisoned, $D=$ decoupled, P-D=poisoned and decoupled.

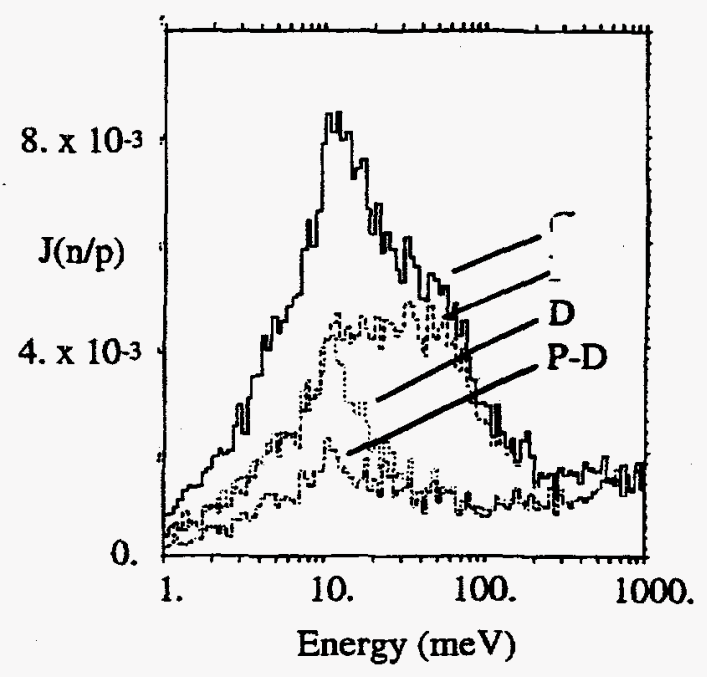

A genera maintenance cell is located behind the target maintenance cell primarily to maintain the moderator/reflector plug, proton beam window, neutron guide tubes and shutters. Generally all operations will be remote; however, personnel may enter the cell following extensive cleanup.

The enclosed, unshielded high-bay above the target system and maintenance cells will provide the primary means of handling components in the target system.

\subsection{CONCLUSIONS}

Preliminary design and analysis indicate that a very attractive short-pulse neutron source operating at $1 \mathrm{MW}$ of proton beam power can be constructed for the NSNS using liquid mercury as the target material. Research and development activities have been identified to validate design concepts and to allow future upgrades to higher power levels. Reasonable design configurations have been proposed for major component assemblies and remote handling concepts have been developed. A detailed descriptions of the NSNS project can be found in Ref. 1.

\section{REFERENCES}

1. "The National Spallation Neutron Source Conceptual Design Report," ORNL, in press, June, 1997. 